\title{
Effects of Light-Rail Transit on Traffic in a Travel Corridor
}

\author{
Reid Ewing, Guang Tian, Allison Spain, and J. P. Goates \\ University of Utah
}

\begin{abstract}
An important debate is taking place over the value of transit in easing traffic congestion. This study sought to quantify the effect of light rail transit (LRT) on traffic in a travel corridor and provide quantitative data that can be used to shape future transportation policies aimed at reducing traffic congestion, energy consumption, and air pollution. Using a quasi-experiment design and data before and after the University of Utah's TRAX LRT line was opened, we estimated that traffic on the street with LRT (400/500 South) decreased by 7,500 to 21,700 due to the availability of a high-quality transit serving destinations along the line, and, most important, the University of Utah. Traffic on 400/500 South decreased despite significant development in the corridor and expansion of the university. Based on our estimates, LRT along 400/500 South saves about 362,000 gallons of gasoline and prevents about 7 million pounds of $\mathrm{CO}_{2}$ from being emitted each year.
\end{abstract}

\section{Introduction}

This study sought to quantify the effect of the University of Utah's TRAX light rail line on traffic near the university, providing quantitative data that can be used to shape future transportation policies aimed at reducing traffic congestion, energy consumption, air pollution, greenhouse gas (GHG) emissions, and parking costs. Initial studies conducted by the Utah Transit Authority (UTA) on data collected by the Utah Department of Transportation showed that traffic near the university has fallen to levels not seen since the 1980s, even as the number of students, faculty, and staff at the university has increased. What is less clear is exactly why this occurred. The university is the second-largest traffic generator in the state, and concerted efforts to encourage commuters to use transit to and from the university have resulted in a large number of commuters adopting transit as a primary means of commuting. A survey conducted in 2005 found that nearly a quarter of students, faculty, and staff at the university used transit as a primary mode of transportation to and from campus.

An audit ordered by the Utah State legislature in 2008 found that transit passes issued to students, faculty, and staff at educational institutions recovered just 8 percent of the cost of service; in comparison, other types of passes recovered an average of 24 percent of the 
cost of service. Determining the effect of the TRAX light rail lines serving the University of Utah campus on traffic along parallel arterial streets makes it possible to quantify the savings in traffic congestion, energy consumption, air pollution, and parking costs that such subsidies provide and allows a full evaluation of the partnership between the university and UTA.

Travel demand models have long been used to estimate and evaluate the effects of transportation improvements, such as LRT investments, on network travel flows and times as part of long-range planning studies using four-step models or more sophisticated urban simulation studies. However, these are usually ex ante studies. Few ex post evaluations have been done, and in this sense, the effects of transit on traffic volumes and associated energy consumption and air pollution have not been rigorously evaluated to support or refute the justification for subsidized transit. Such quantification is required for a comprehensive cost-benefit analysis. Transit is assumed to reduce traffic congestion and alleviate the negative impacts of congestion. The introduction of TRAX light rail service to the university provides a quasi-experiment from which we can quantify the before-and-after impacts of transit. Our aim was to provide the first hard evidence of light rail's impact on traffic in a travel corridor; quantify the associated savings on energy consumption and air pollution.

\section{Literature Review}

Many regions around the United States are developing LRT systems as an alternative to the automobile. LRT has become an attractive option because of its ability to be located in a variety of land use contexts, from suburbs to high-density central business districts. Living near LRT stations offers an array of benefits that have been measured through several studies. These benefits arise from lower transportation costs, more compact development patterns, higher property values, and reduced air pollution.

\section{Traffic}

The statement "you can't pave your way out of congestion" is generally accepted. Litman (2010) identifies errors in the arguments for highway expansion to reduce traffic congestion. As an alternative, LRT has the potential to reduce regional traffic congestion because it does not (unlike highway expansion) induce additional regional vehicle miles traveled (VMT). Indeed, from recent studies, it has the opposite effect (Hyman and Mayhew 2002; Schrank, Eisele, and Lomax 2012; Ewing et al. 2008; Cervero and Murakami 2010; Ewing et al. 2014).

The Texas A\&M Transportation Institute's (TTI) 2012 Urban Mobility Report reports that in the 498 urban areas studied, there were approximately 56 billion passenger miles of travel on public transportation systems in 2011 (Schrank, Eisele, and Lomax 2012). Overall, if these riders were not handled on public transportation systems, they would contribute an additional roadway delay of almost 865 million hours, or about a 15 percent increase in the total delay. Of the 865 million hours of potential extra delay, 816 million were estimated to be in 101 larger urban areas, including Salt Lake City and Provo-Orem, Utah.

Regional studies also show that LRT development affects vehicular traffic congestion. Research by Winston and Langer (2006) indicates that both motorists and truck congestion costs decline in a city as rail transit mileage expands. Garrett and Castelazo (2004) 
found that traffic congestion growth rates declined in several U.S. cities after LRT was established. A study of traffic congestion in Denver indicated that traffic within the zone of influence of the LRT system increased 31 percent compared with 41 percent outside the zone of influence (Bhattacharjee and Goetz 2012). A study in Baltimore showed that congestion increased an average of 2.8 percent annually before light rail, but only 1.5 percent annually after light rail was implemented (Litman 2012). Litman (2012) also found that cities with rail systems have significantly higher per-capita transit ridership and lower per-capita vehicle ownership than cities with no rail transit service. Goldstein (2007) found that households located within walking distance of rail transit stations drive 30 percent less on average than those located in less transit-accessible locations.

However, Senior (2009) and Lee et al. (2013) questioned the effect of LRT on car ownership and car use. They argued that rail ridership increases come from bus trips that are diverted to rail. They concluded that light rail was only somewhat successful in decreasing car use for journeys to work and, at best, made only a minimal impact on road congestion, partly because of the lack of coordinated car restraint policies. Duranton and Turner (2011) also found no evidence that public transportation relieves road congestion, arguing that whenever a driver shifts onto public transportation, another is going to use the open lane.

\section{Air Pollution}

TTI's 2012 Urban Mobility Report reports that 380 pounds of $\mathrm{CO}_{2}$ were emitted per auto commuter during congestion in 2011 vs. 160 in 1982(Schrank, Eisele, and Lomax 2012). The effects of transit on air pollution and GHG emissions are subject to debate. Using structural equation modeling, Ewing et al. (2008) and Bailey et al. (2008) found that transit service reduces urban VMT and associated emissions both directly through mode shifts and indirectly through land use changes. In a holistic approach measuring the impacts of transit in Washington DC, Los Angeles, and London, Parry and Small (2009) showed the benefits of subsidizing urban transit: substantial reductions in congestion, pollution, and traffic accidents.

On the other hand, O'Toole (2008) questioned the supposed reduction in energy GHG emissions from public transportation. The substantial fossil fuel consumption by public transport does not guarantee that a city will save energy or meet GHG targets by investing in public transportation. Since public transportation generally uses diesel fuels and electricity, the mix of pollutants emitted by public transportation must be considered as an offset to automobile pollution reduction.

From our literature review, we found no study that used a similar, carefully-controlled research design to estimate the effects transit has on traffic, energy consumption and air pollution in a travel corridor.

\section{Longitudinal Analyses and Natural Experiments}

The vast majority of studies on travel and the built environment are cross-sectional in nature, using travel data at a single point in time to explain travel behavior. Transportation Research Board (TRB) Special Report 282, "Does the Built Environment Influence Physical Activity? Examining the Evidence" (TRB 2005), calls for longitudinal studies that use data for the same places over time to explain changes in behavior. These are rare 
because longitudinal data are rare. According to the TRB, "... most of the studies conducted to date have been cross-sectional. Longitudinal study designs using time-series data are also needed to investigate causal relationships between the built environment and physical activity" (TRB 2005, 7). The same need exists in studies of travel behavior.

TRB Special Report 282 also calls for studies of so-called natural experiments, changes that occur naturally when some public or private action alters the built environment. If baseline data are available, the effect of the change can be quantified. "When changes are made to the built environment-whether retrofitting existing environments or constructing new developments or communities-researchers should view such natural experiments as 'demonstration' projects and analyze their impacts on physical activity" (TRB 2005, 12). Again, the same opportunity exists when natural experiments alter travel behavior.

Such natural experiments occur every time a new transit line is built. Well-located transit lines will attract new development, changing the built environments of the station areas. We would expect to see a corresponding change in travel behavior.

\section{UTA's Rail System}

UTA's initial LRT line (the Blue Line) opened in 1999. It runs from downtown Salt Lake City to Sandy, a suburban community in southern Salt Lake County. In August 2000, construction began on an extension from downtown to the University of Utah's southwest corner at the Rice-Eccles Stadium (the Red Line); that line opened in December 2001. In May 2002, work began on an extension of the University TRAX line to the University Medical Center at the northeast corner of campus; that line opened in September 2003 (see Figure 1).

Since then, UTA's LRT system has been expanded as follows:

- August 2011 - 5.1-mile, 4-station extension of the Green Line to the West Valley City Center

- August 2011 - 10.6-mile, 9-station extension of the Red Line to Daybreak in South Jordan

- April 2013 - 6-mile, 6-station extension of the Green Line to the Salt Lake International Airport

- August 2013 - 3.5-mile, 3-station extension of the Blue Line to Draper 
FIGURE 1.

UTA rail system map

\section{TRAX \& FRONTRUNNER MAP U T A $\rightleftharpoons$}

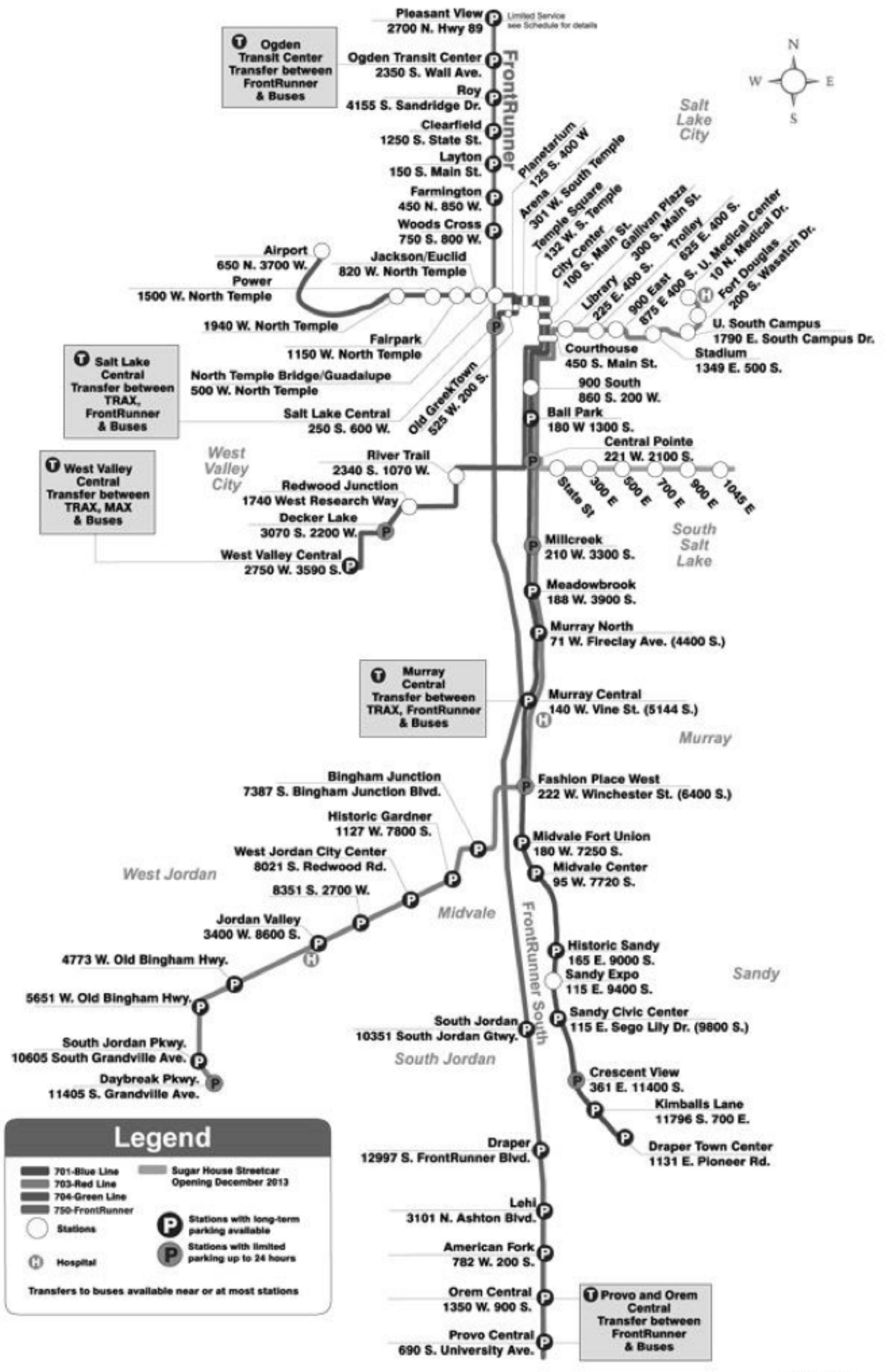


Each of these rail extensions represents a natural experiment that can be studied for its impacts on travel within the rail corridor by comparing conditions before the extension to conditions after the extension. This study focuses on the university extension because adequate time has passed since the extension was built for the full effects to be felt. The university extension is also interesting because it has the highest ridership on the system (see Table 1). The system is free for students, as part of tuition and registration fees. Those holding tickets to all University of Utah home games can ride the TRAX for free. The University line has short headways during the peak period (15-minute headways). The university is a commuter school, and the TRAX line serves heavy traffic from the downtown hub and points south and west. There is local promotion by city government to use TRAX for air pollution reduction.

TABLE 1.

Ridership on the UTA's Rail System (2012)

\begin{tabular}{|l|c|}
\hline \multicolumn{1}{|c|}{ TRAX } & Nov 2011-Oct 2012 \\
\hline Blue Line & 21,200 \\
\hline Red Line & 22,200 \\
\hline Green Line & 9,500 \\
\hline
\end{tabular}

\section{Quasi-Experimental Analysis}

A quasi-experiment is an empirical study used to estimate the causal impact of an intervention on its target population. Quasi-experimental research designs share some characteristics with traditional experimental designs, such as the treatment of one group but not another. Where the two designs differ is in the lack of random assignment of subjects to treatment and control groups.

A causal inference from any quasi-experiment must meet the basic requirements for all causal relationships: that cause precedes effect; that cause covaries with effect; and that alternative explanations for the causal relationships are implausible (Shadish et al. 2002). Both randomized and quasi-experiments force the treatment to occur before the effect. Assessing covariation between cause and effect is easily accomplished in all experiments, usually using statistical analysis. To meet the third requirement, randomized experiments make alternative explanations implausible by ensuring that subjects are randomly distributed across experimental conditions. Without random assignment, quasi-experiments rely on statistical control variables and sample matching to show that alternative explanations are implausible.

\section{The "Treatment"}

The "treatment" in this quasi-experiment is the 2.3-mile extension of TRAX from downtown Salt Lake City to Rice-Eccles Stadium in December 2001 (see Figure 2). Year 2001 represents the last year before the initial treatment, and 2002 represents the first year after the treatment. Construction began on the 1.5-mile University Medical Center Extension in May 2002, and the line opened at the end of September 2003. This opening constitutes a second treatment. The last year before this treatment is 2003, and the first year after is 2004. 


\section{The University TRAX Line}

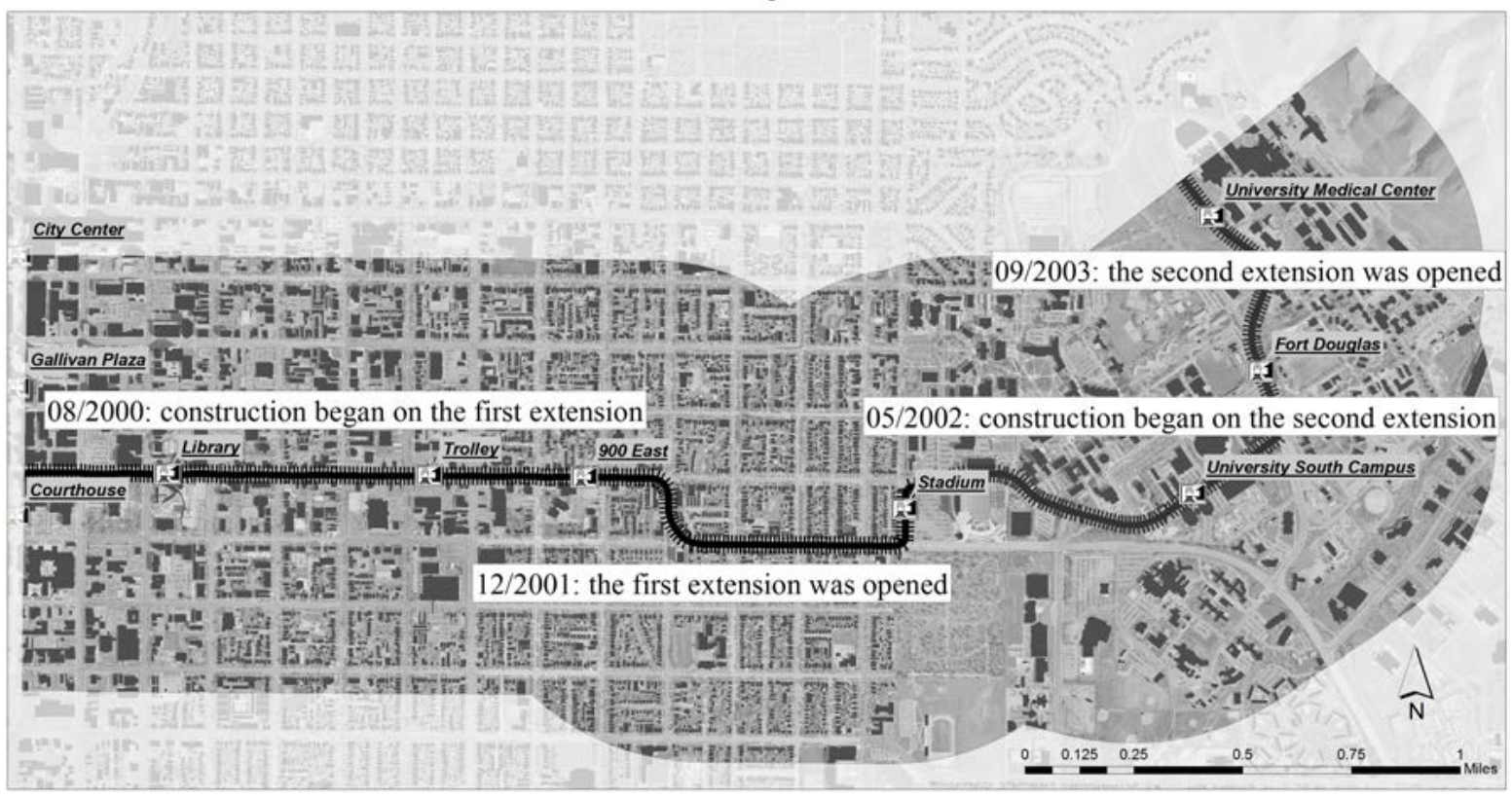

FIGURE 2. Timeline of University TRAX Line

\section{Short-Term Impact of TRAX: Pre-test/Post-test without a Comparison Group}

Our first analysis used the simplest quasi-experimental design, a one-group pre-treatment, post-treatment design with no comparison group. This can be diagrammed as follows, where $O$ is an observation and $X$ is a treatment. The "treatment" in this case is the opening of the University TRAX line:

$$
\mathrm{O}_{1} \mathrm{X}^{\mathrm{O}_{2}}
$$

This research design is classified as a "weak" quasi-experimental design, because it lacks a control or comparison group. "Adding a pre-test provides weak information about the counterfactual inference about what might have happened to participants had the treatment not occurred ... because [observation 1] occurs before [observation 2], the two may differ for reasons unrelated to treatment, such as maturation or history" (Shadish et al. 2002, p. 108). All of the difference in an outcome from before the treatment to after the treatment is attributed to the treatment itself.

In this simple model of the world, we would assume that the effect of the University TRAX line on traffic is just the drop in annual average daily traffic (AADT) on 400/500 South in the year before TRAX opened compared to the year after TRAX opened. This difference is $\Delta 1$ in Figure 3. The drop in AADT on $400 / 500$ South was 9,300 vehicles per day (vpd) between 2001 and 2002. The line opened in December 2001, so we can assume that all of 2001 represents the before condition and all of 2002 represents the after condition. 
FIGURE 3.

AADT on $400 / 500$ South, TRAX ridership along 400/500 South, and bus ridership along 400/500 South

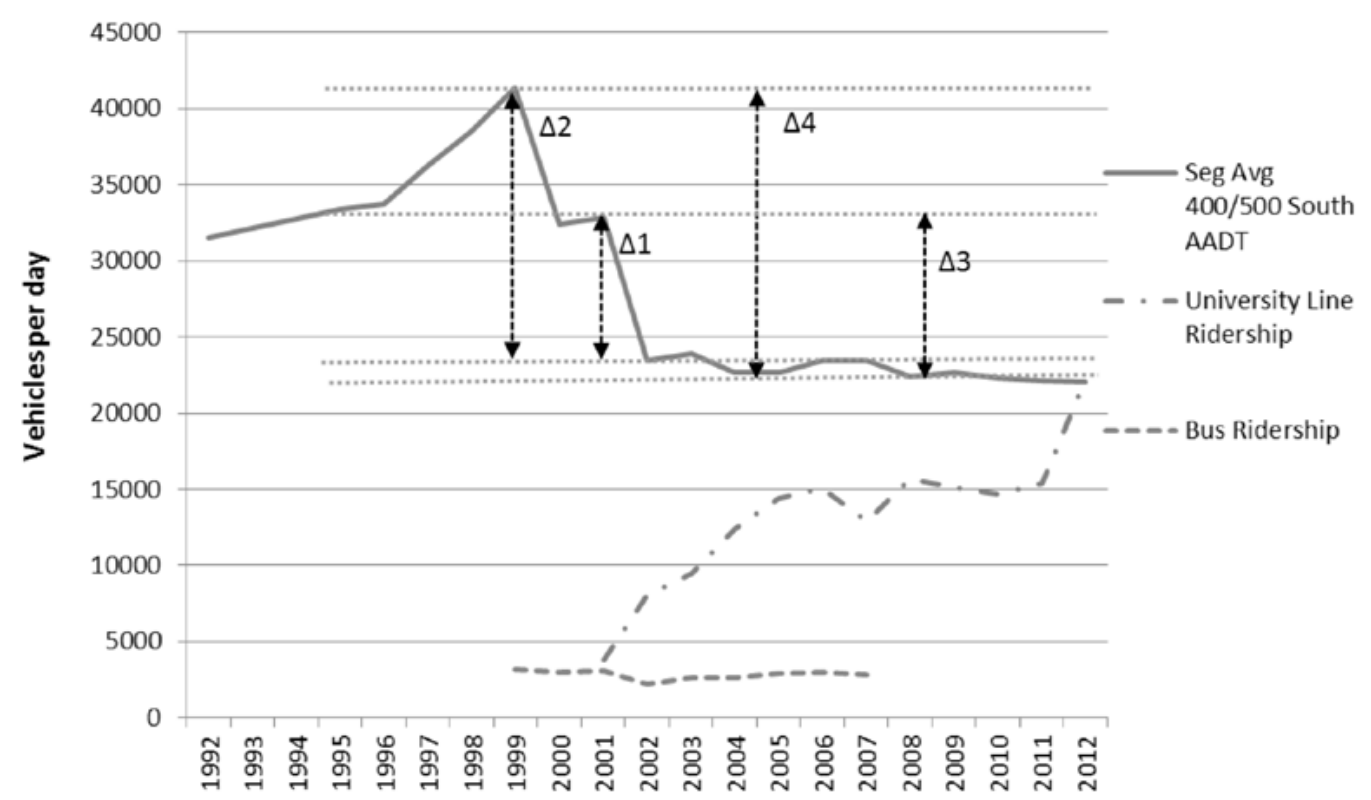

Figure 3 shows that TRAX ridership continued to increase after 2002. Part of that increase in TRAX ridership is doubtless due to the extension of the University TRAX line to the $U$ of $U$ Medical Center in late September 2003. This extension added three stops and 1.5 miles to the line. A small dip can be seen in AADT on 400 South between 2003 and 2004. The net decrease in traffic on 400/500 South between 2001 and 2004 is represented by $\Delta 3$ in Figure 3 .

Several factors, however, complicate the picture. First, the AADT on $400 / 500$ South was higher in prior years and had been increasing starting in 1992 and running through 1999. Construction of TRAX in 2000 and 2001 and the resulting disruption of traffic operations on 400/500 South seem to have depressed AADT. If one assumes that the "before" condition is actually represented by AADT in 1999, the effect of TRAX is twice that estimated above, or $\Delta 2$. The decline in AADT between 1999 and 2002 was 17,900 vpd.

TABLE 2.

Effect of TRAX on Traffic on 400/500 South

\begin{tabular}{|c|c|c|}
\hline & AADT on 400 South & Net Transit Ridership \\
\hline$\Delta 1$ & $-9,300$ & 7,200 \\
\hline$\Delta 2$ & $-17,900$ & 7,100 \\
\hline$\Delta 3$ & $-10,100$ & 12,800 \\
\hline$\Delta 4$ & $-18,700$ & 12,000 \\
\hline
\end{tabular}

Second, traffic increased on some streets parallel to 400/500 South between 2001 and 2004, suggesting that not all of the decline on 400/500 South was due to TRAX; some was due to diversion to parallel streets (see Figure 4). AADT increased by a net amount of 3,600 on parallel streets between 2001 and 2004 (see Table 3). So most, but not all, of the reduction in AADT on 400 South appears to be due to TRAX. 


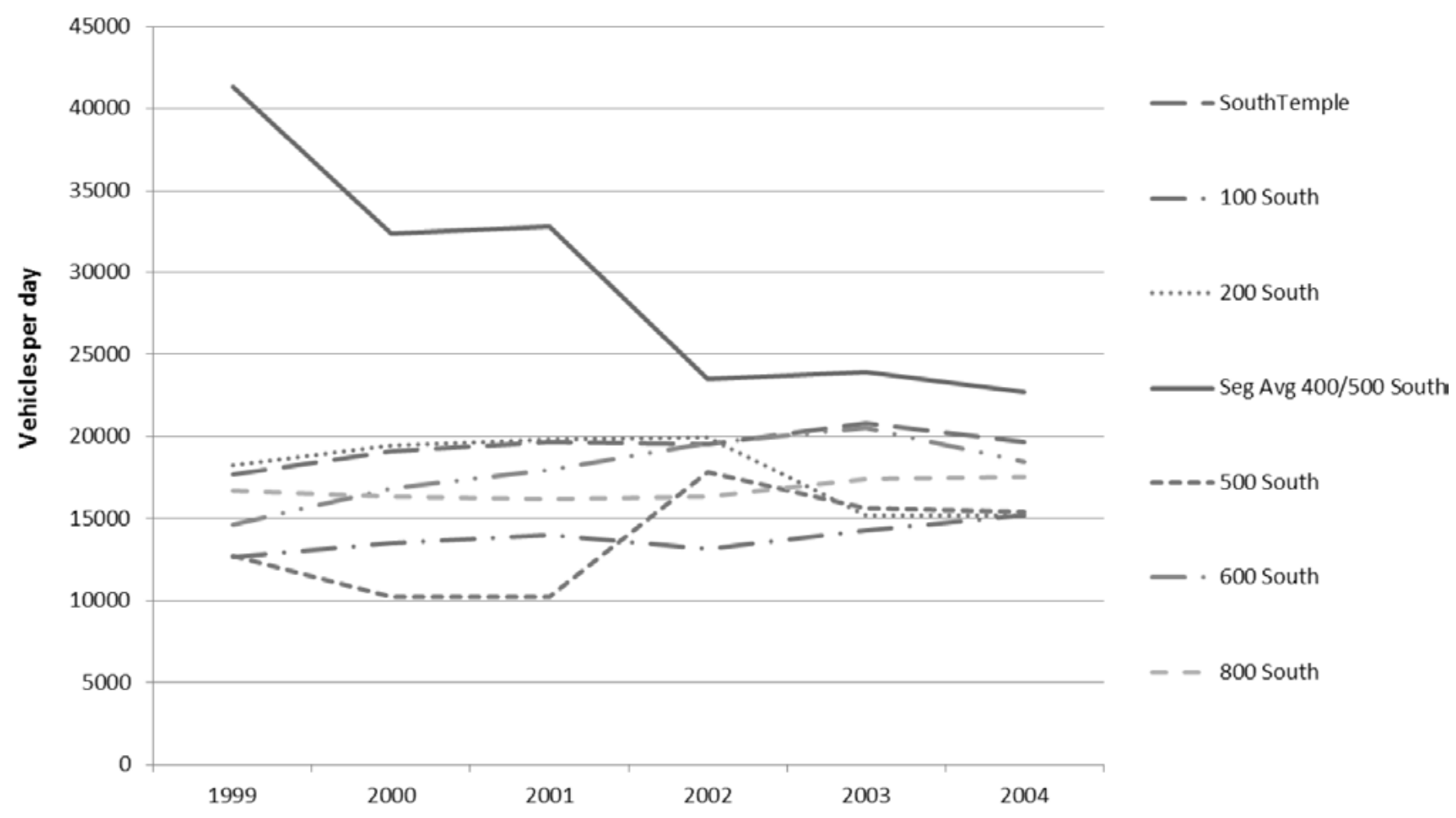

FIGURE 4. AADT on streets parallel to TRAX

TABLE 3.

Change in AADT between 2001 and 2004

\begin{tabular}{|l|c|c|c|}
\hline \multirow{2}{*}{ Location } & \multicolumn{2}{|c|}{ Change in ADT from 2001 to 2004 } & Distance from \\
\cline { 2 - 3 } & Absolute change & Percentage (\%) & 400 South (mi) \\
\hline South Temple & -20 & -0.10 & 0.76 \\
\hline 100 South & 1,200 & 8.68 & 0.6 \\
\hline 200 South & $-4,600$ & -23.2 & 0.46 \\
\hline Seg avg 400/500 South & $-10,100$ & -30.82 & 0 \\
\hline 500 South & 5,200 & 50.41 & 0.4 \\
\hline 600 South & 500 & 2.88 & 0.55 \\
\hline 800 South & 1,300 & 8.1 & 0.84 \\
\hline
\end{tabular}

Third, the net increase in transit ridership is less than 7,200 riders because some of the riders were diverted from buses. There were six bus lines running along 400/500 South from 1999 to 2001, and the total daily ridership was approximately 3,000 passengers. In August 2002, three bus lines were dropped, and two more were added. Total bus ridership declined, but only marginally. This is treated as a slight offset against TRAX ridership (see Table 4). 


\section{TABLE 4.}

Bus Ridership on 400/500 South

\begin{tabular}{|c|c|c|c|c|c|c|c|c|c|c|c|c|c|c|c|c|}
\hline \multicolumn{17}{|c|}{ Criteria: West-East Direction; through $400 / 500$ South } \\
\hline \multirow{2}{*}{ Line } & \multirow{2}{*}{ Line Name } & \multirow{2}{*}{1999} & \multirow{2}{*}{2000} & \multirow{2}{*}{2001} & \multicolumn{2}{|c|}{2002} & \multirow{2}{*}{2003} & \multirow{2}{*}{2004} & \multirow{2}{*}{2005} & \multirow{2}{*}{2006} & \multicolumn{2}{|c|}{2007} & \multirow{2}{*}{2008} & \multirow{2}{*}{2009} & \multirow{2}{*}{2010} & \multirow{2}{*}{2011} \\
\hline & & & & & 2002.8 & 2002.8 & & & & & 2007.8 & 2007.8 & & & & \\
\hline 13 & Canyon Rim & 460 & 495 & 462 & 353 & & & & & & & & & & & \\
\hline 14 & East Millcreek & 606 & 686 & 604 & 454 & 704 & 687 & 724 & 778 & 806 & 708 & & & & & \\
\hline 29 & Wasatch Blvd via $U$ of Utah & 459 & & & & & & & & & & & & & & \\
\hline 52 & U of Utah & 1,109 & 1,061 & 1,088 & 739 & & & & & & & & & & & \\
\hline 54 & Olympus Cove & 93 & 299 & 435 & & & & & & & & & & & & \\
\hline 55 & U of Utah/Davis Co/Weber St & & & & & 1,089 & 1,176 & 1,193 & 1,221 & 1,222 & 1,147 & & & & & \\
\hline 71 & Centerville via Orchard Dr & & & & & 228 & 260 & 244 & 311 & 398 & 340 & & & & & \\
\hline 73 & Hwy 89 Express & 333 & 367 & 386 & 374 & 420 & 455 & 443 & 525 & 543 & 554 & & & & & \\
\hline 129 & U of Utah/Foothill Dr Nite Ride & 131 & 127 & 104 & 59 & 66 & 65 & 54 & 51 & 66 & 53 & & & & & \\
\hline 228 & Foothill Blvd/2700 East & & & & & & & & & & & & & & & $\mathrm{Y}$ \\
\hline 455 & $\mathrm{U}$ of Utah/Davis Co/WSU & & & & & & & & & & & $\mathrm{Y}$ & $\mathrm{Y}$ & $\mathrm{Y}$ & $\mathrm{Y}$ & $\mathrm{Y}$ \\
\hline 471 & Centerville via Orchard Dr & & & & & & & & & & & $\mathrm{Y}$ & $\mathrm{Y}$ & & & \\
\hline \multirow[t]{3}{*}{473} & SLC-Ogden Hwy 89 Express & & & & & & & & & & & $\mathrm{Y}$ & $\mathrm{Y}$ & $\mathrm{Y}$ & $\mathrm{Y}$ & $\mathrm{Y}$ \\
\hline & & & & & 1,978 & 2,506 & & & & & & & & & & \\
\hline & Sum & 3,191 & 3,034 & 3,080 & 2,242 & 2,642 & 2,658 & 2,887 & 3,035 & 2,802 & & & & & & \\
\hline
\end{tabular}


If one adds the net transit ridership increase between 2001 and $2004(6,800)$ to the net increase in AADT on parallel streets $(3,600)$, one arrives at a number roughly equivalent to the drop in AADT on $400 / 500$ South $(10,100)$. This simple accounting gives a rough order-of-magnitude estimate of TRAX's impact on traffic.

\section{Medium-Term Impact of TRAX - Pre-test/Post-test with a Comparison Group}

TRAX ridership continued to increase after 2004, when the full line was in operation. Ridership does not level off until 2008-2011. The dip in 2007 is likely due to issues with a passenger counting system that UTA implemented in 2007, as well as to construction in downtown Salt Lake City and consumer willingness to pay higher prices for gasoline, according to an article in the Deseret News (Warburton 2007).

New transit lines often have a break-in period when travel patterns evolve as riders "discover" the new transit option. To estimate the medium-term impact of TRAX on traffic, we needed to account for general trends in the study area. This required a more sophisticated quasi-experimental design, a design that included both a pre-treatment observation and a control or comparison group. According to the "bible" of quasi-experimental design, Shadish, Cook, and Campbell's Experimental and Quasi-Experimental Designs for Generalized Causal Inference, "The joint use of a pre-test and a comparison group makes it easier to examine certain threats to validity [causal inference]. Because the groups are nonequivalent by definition, selection bias is presumed to be present. The pre-test allows exploration of the possible size and direction of that bias...." (Shadish et al. 2002, p.138).

This typically is done by seeing if the treatment and control groups differ significantly before the treatment. The absence of pre-treatment difference in a quasi-experiment does not prove that selection bias is absent, but it makes it less likely. Regression-tothe-mean is the statistical tendency of values above the mean in one period to gravitate downward toward the mean in the next period, and those below the mean in one period to gravitate upward toward the mean in the next period.

Ideally, we would match 400/500 South with another street that is very similar to 400/500 South before the University TRAX line opened, a street not particularly affected by the line. The two streets that mostly closely match 400/500 South are 700 East and 1300 East (see Figure 5). These are north-south streets that intersect TRAX but do not offer park-and-ride options and, hence, should not be appreciably affected by the opening of the University TRAX line. Like 400/500 South, 700 East is a six-lane arterial serving the northeast quadrant of the city. However, 700 East carried significantly more traffic, even before TRAX. Like 400/500 South, 1300 East serves the university directly. However, 1300 East had only four lanes before the opening of TRAX and carried much less traffic. Interestingly, it now carries almost as much traffic as 400/500 South, yet is down to three lanes south of campus after a "road diet" narrowing in 2009. 


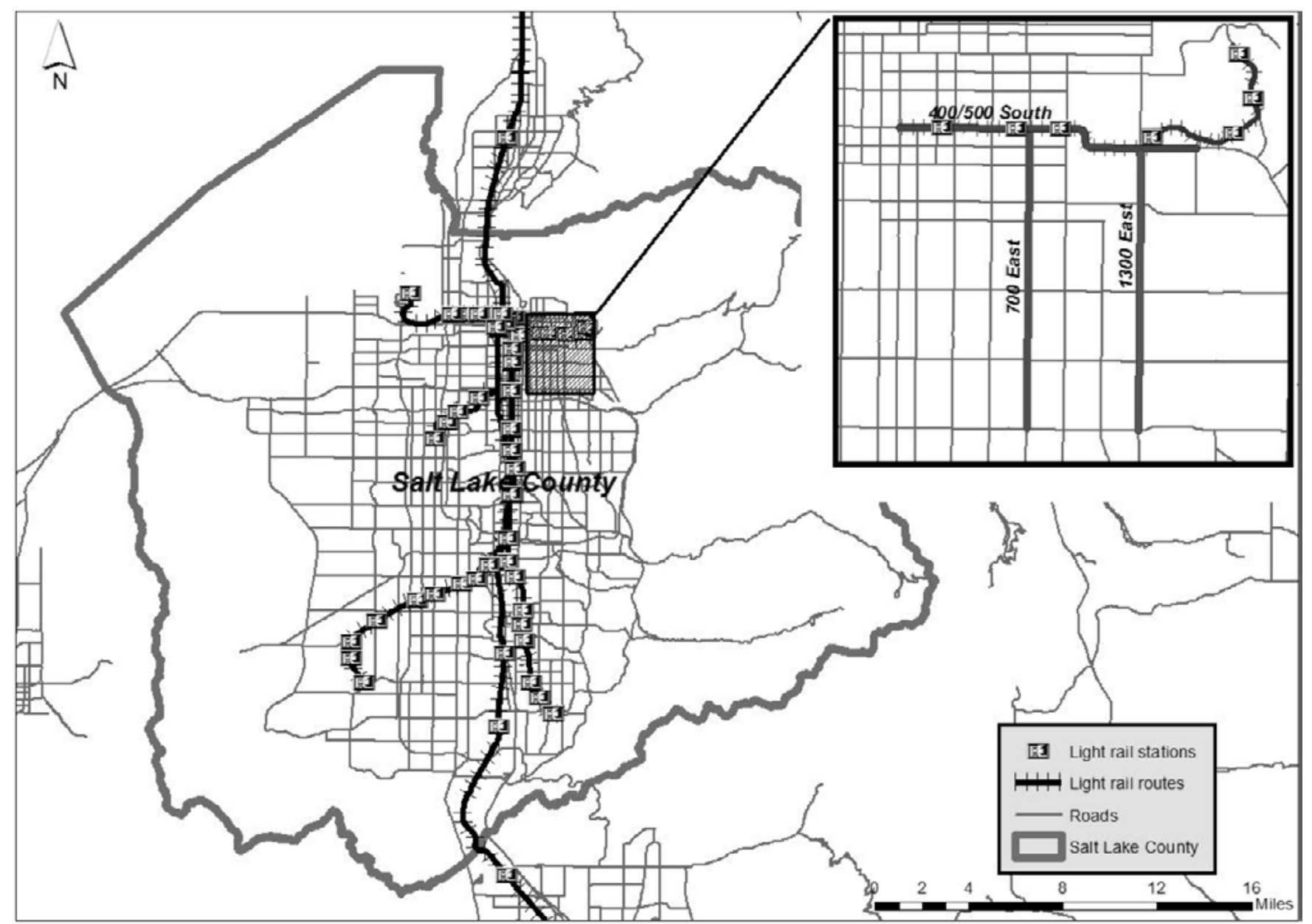

FIGURE 5. 400/500 South and comparison roads (700 East and 1300 East)

Although neither 700 East nor 1300 East is a perfect match to $400 / 500$ South, it turns out that the average AADT on these two streets was virtually identical to the AADT on $400 / 500$ South before the University TRAX line opened. We used this average as our control in this quasi-experimental analysis. As can be seen in Figure 6, the average AADT for the two streets dips after 2001, as it does on 400/500 South, but it does not dip as far. It is not clear why traffic volumes would decline on these two streets, but this trend needs to be accounted for in a pre-test/post-test design with a comparison group. Assuming the counterfact that traffic on 400/500 South would have tracked exactly with these two streets in the absence of TRAX, $\triangle 5$ becomes our estimate of the reduction in traffic on $400 / 500$ South due to TRAX. For the years 2006-2012, the average AADT on these two north-south streets was 7,500 vpd higher than the AADT on 400/500 South. This is less than our estimates in a simple pre-treatment/post-treatment comparison of traffic on $400 / 500$ South and represents a better estimate than attainable with the simpler design. 
FIGURE 6.

Average AADT on 700 East and 1300 East

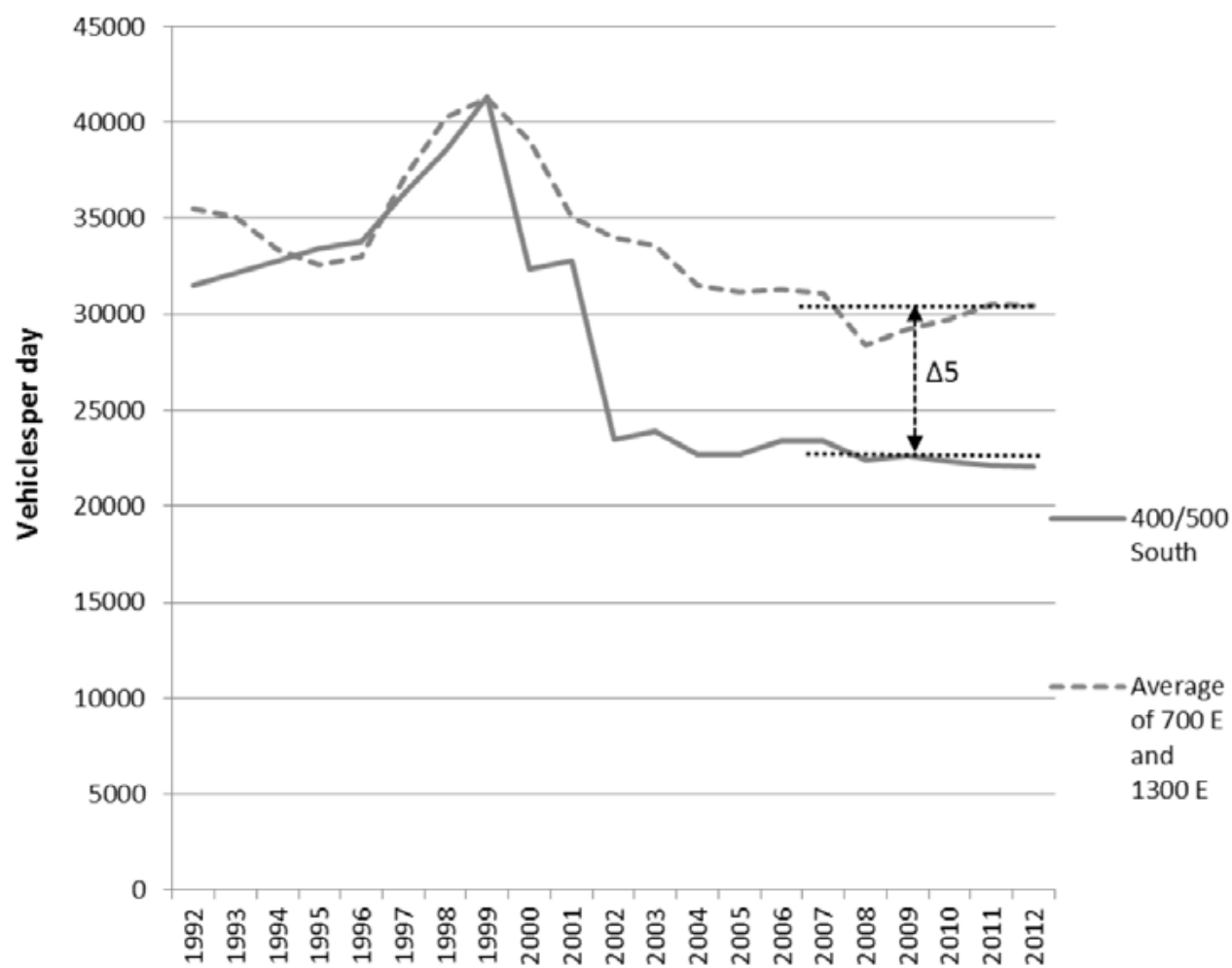

We checked this long-run estimate of TRAX's impact on 400 South traffic against transit ridership. The net transit ridership increase between 2001 and 2006-2012 is 12,700 passengers per day (15,800 average for 2006-2012 minus 3,100 for 2001). Specifically, the decline in AADT on $400 / 500$ South $(7,500)$ is 41 percent less than the increase in transit ridership. This simple accounting comparison makes the estimate of TRAX's impact seem plausible. The drop in AADT on 400/500 South would necessarily be less than the increase in transit ridership since not every transit trip replaces a drive-alone vehicle trip.

\section{Land Use Changes}

A final quasi-experimental analysis assumed that, without TRAX, traffic on 400/500 South would have increased proportionally with development in the corridor or, more specifically, increased proportionally with traffic generated by that development. For this analysis, the corridor was assumed to extend a half-mile north and south of 400/500 South to South Temple on the north and 800 South on the south (see Figure 7). Parcels that changed between 1999 and 2009 (were developed, redeveloped, or cleared) are highlighted in black. 
FIGURE 7.

Parcels that changed between 1999 and 2009 (areas in black)

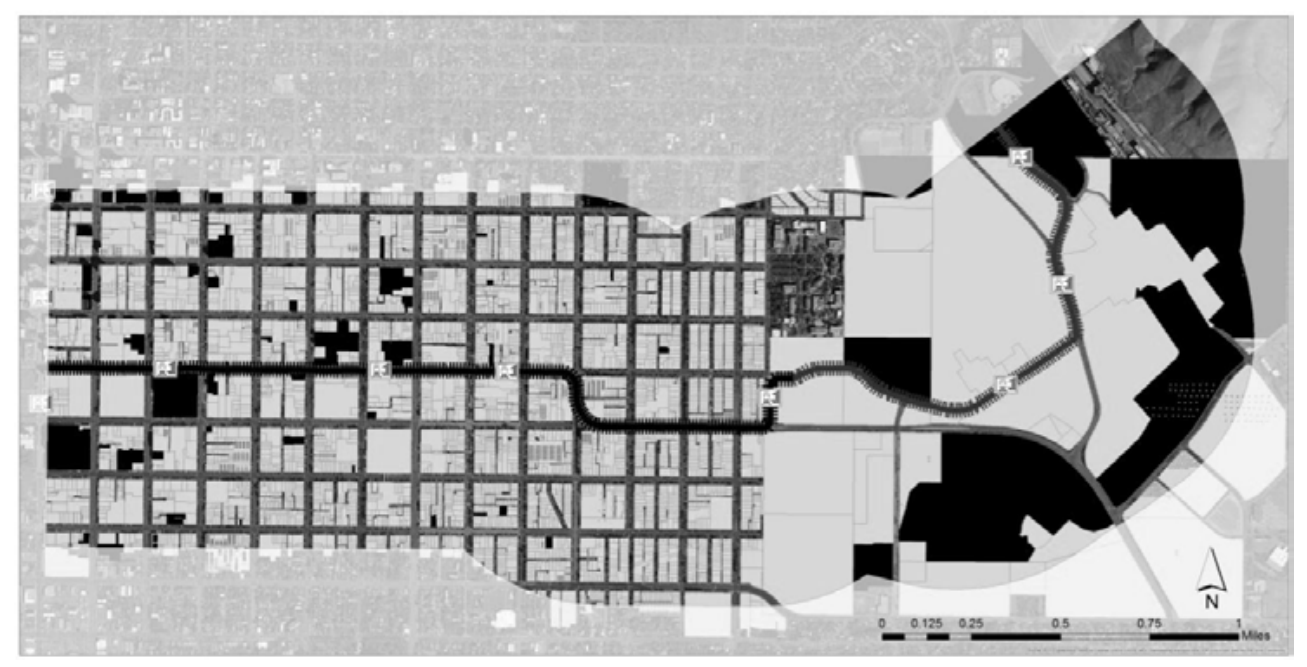

We identified changes by comparing aerial photos for 1999 and 2009 parcel-by-parcel and also by comparing tax assessor records for the two years. Building floor area was available from tax assessor records only for 2009. Building floor area in 1999 was set equal to that in 2009 where the building footprint did not change. Where the footprint did change, floor area in 1999 was estimated from the 1999 aerial photo assuming buildings were single-story.

Building floor area changes in the 400/500 South corridor are summarized in Table 5. The vast majority of the changes involved construction on vacant land ( 99 of 269 parcels), and the vast majority of new development was commercial, followed by public and then residential.

TABLE 5.

Changes of Building Floor Area by Land Use Type between 1999 and 2009 for Parcels that Changed

\begin{tabular}{|l|r|r|r|}
\hline \multicolumn{1}{|c|}{ Land Use Type } & \multicolumn{1}{c|}{1999} & \multicolumn{1}{c|}{2009} & \multicolumn{1}{c|}{ Change } \\
\hline Residential & 48,300 & 794,000 & 745,800 \\
\hline Commercial & $1,712,200$ & $4,870,500$ & $3,158,400$ \\
\hline Public & $10,854,100$ & $13,445,000$ & $2,590,900$ \\
\hline Other (e.g., parking lots) & 46,800 & 3,500 & $-43,400$ \\
\hline Total building square footage & $12,661,400$ & $19,113,000$ & $6,451,700$ \\
\hline
\end{tabular}

Table 6 provides a summary of total development in the corridor and land use type in 1999 and 2009. The gross floor area of all buildings increased from 50,567,600 square feet to $57,019,200$ square feet over the decade, an increase of $6,451,700$ square feet or 12.8 percent. It is impossible to say how much of that additional development was due to TRAX. However, the corridor became more developed over the decade, concurrent with the opening of TRAX and, surprisingly, traffic on 400/500 South actually declined despite increased development in the corridor. We are aware of no similar finding in the literature. 
TABLE 6.

Total Building Floor Area in the $400 / 500$ South Corridor

by Land Use Type

\begin{tabular}{|l|r|r|r|}
\hline \multicolumn{1}{|c|}{ Land Use Type } & \multicolumn{1}{c|}{1999} & \multicolumn{1}{c|}{2009} & \multicolumn{1}{c|}{ Change } \\
\hline Residential & $11,173,000$ & $11,918,800$ & 745,800 \\
\hline Commercial & $19,851,100$ & $23,009,400$ & $3,158,400$ \\
\hline Public & $16,424,000$ & $19,014,900$ & $2,590,900$ \\
\hline Other & $3,119,500$ & $3,076,100$ & $-43,400$ \\
\hline Total building square footage & $50,567,600$ & $57,019,200$ & $6,451,700$ \\
\hline
\end{tabular}

Using trip generation rates from the Institute of Transportation Engineers' (ITE) Trip Generation report (ITE 2012), we estimated total trips generated by properties within the 400/500 South Corridor. 'Trip generation totals by land use type are presented in Table 7. Trips rates from ITE actually refer to trip ends, either origins or destinations. Trips beginning in the corridor and destined outside are counted only once. Trips beginning outside the corridor and destined inside are also counted only once. Those beginning and ending within the corridor are counted twice, and those simply traveling through the corridor, with origins and destinations outside, are not captured at all with our method. Hence, there is no simple one-to-one relationship between trips generated within the corridor, and traffic on $400 / 500$ South.

TABLE 7.

Total Trip Generation by Land Use

\begin{tabular}{|l|r|r|r|}
\hline Land Use Type & \multicolumn{1}{c|}{1999} & \multicolumn{1}{c|}{2009} & Change \\
\hline Residential & 77,000 & 86,200 & 9,200 \\
\hline Commercial & 834,500 & 861,000 & 26,500 \\
\hline Public & 226,100 & 276,500 & 50,400 \\
\hline Other & 500 & 4,400 & 3,900 \\
\hline Total & $1,138,100$ & $1,228,100$ & 90,000 \\
\hline
\end{tabular}

Nonetheless, we assumed that in the absence of TRAX, there would be rough proportionality between traffic generated within the corridor and non-thru traffic on 400/500 South. If the former increases by 7.9 percent, as we calculated, it is reasonable to assume that traffic on the main east-west street through the corridor would also increase by 7.9 percent. The regional travel model predicts that 1.4 percent of the traffic on $400 / 500$ South is thru-traffic, leaving 98.6 percent $(40,800)$ as local. ${ }^{2}$ So for our last estimate of

${ }^{1}$ For University of Utah trip generation, we categorized university buildings into four classes: Hospital,
University Housing, Research Park, and Main Campus. Trip rates were 16.5 per 1,000sf for Hospital, 6.11
per 1,000sf for Research Park, 1.71 per student, and 8.96 per employee for the main campus. For university
housing, the trip rate depends on the type of the housing, such as dorms, apartment and family house. Total
trip generation for main campus is shown in the table below.

\begin{tabular}{|l|c|c|c|c|c|}
\hline \multirow{2}{*}{} & \multicolumn{2}{|c|}{ Students } & \multicolumn{2}{c|}{ Employment } & \multirow{2}{*}{ Trips } \\
\cline { 2 - 5 } & Number & Trip Rate & Number & Trip Rate & \\
\hline 1999 & 25,781 & 1.71 & 3,070 & 8.96 & 71,600 \\
\hline 2009 & 29,284 & 1.71 & 3,582 & 8.96 & 82,200 \\
\hline
\end{tabular}

${ }^{2}$ The regional model shows that there are about 2,200 trips per day between downtown (defined as the area between State and I-15 and South Temple and 900 South) and the area east of Guardsman Way and North of 900 South. This accounts for 1.4 percent of the east/west trips within half mile of 400 South. 
TRAX's impact on traffic, we assumed a counterfactual that local traffic on 400/500 South would have increased by 7.9 percent in the absence of TRAX, from 40,800 in 1999 (98.6 percent of actual count) to 44,000 in $2009(1.079 \times 40,800)$. The difference between this estimate for 2009 and our estimate of actual local traffic volume in $2009(22,300)$, $21,700(44,000-22,300)$, is the estimated effect of TRAX. It is shown as $\Delta 6$ in Figure 8. Note that these numbers explicitly exclude thru-traffic between State Street on the west and Guardsman Way on the east.

FIGURE 8.

Local AADT on 400/500,

estimated local traffic on $400 / 500$ based on trip generation between 1999 and 2009

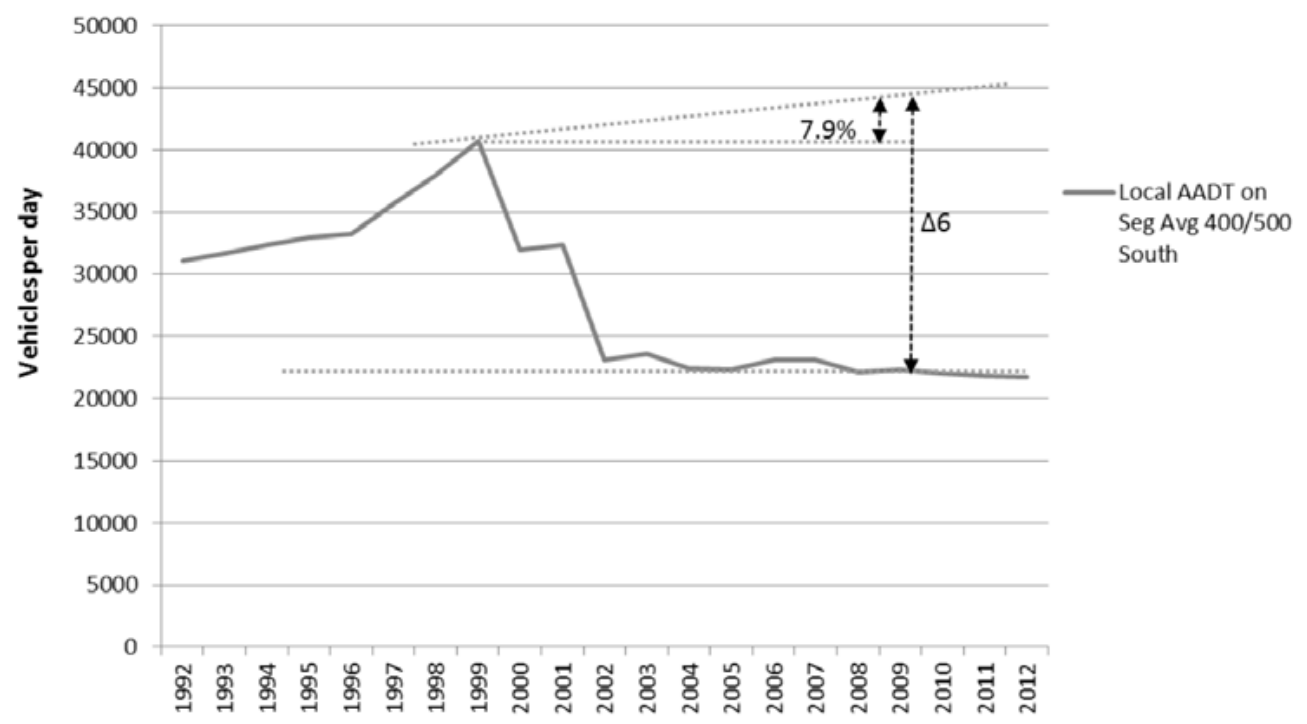

\section{Energy and Emission Reduction}

To summarize, we have six estimates of the impact of TRAX on average daily traffic on 400/500 South, all based on different assumptions and different time frames (see Table 8). We chose a conservative estimate that is roughly mid-range $-14,000$ vehicles per dayfor this summary of impacts. Of the 14,000 vehicle per day drop in traffic on $400 / 500$ South, some were diverted to parallel streets rather than TRAX. We have estimated diversion to parallel streets to be $3,600 \mathrm{vpd}$. Therefore, the net reduction of traffic traveling the corridor would be 10,400 vpd.

TABLE 8.

Estimates of Traffic Reduction on $400 / 500$ South Due to

TRAX

\begin{tabular}{|c|c|}
\hline Estimate & Average Daily Traffic Reduction \\
\hline$\Delta 1$ & 9,300 \\
\hline$\Delta 2$ & 17,900 \\
\hline$\Delta 3$ & 10,100 \\
\hline$\Delta 4$ & 18,700 \\
\hline$\Delta 5$ & 7,300 \\
\hline$\Delta 6$ & 21,700 \\
\hline
\end{tabular}


With the traffic decrease in the corridor of 10,400, there is less fuel consumed and less pollution emitted. According to U.S. Environmental Protection Agency (EPA) data, the average emissions and fuel consumption for passenger cars are shown in Table 9. Multiplying the reduction in vehicle miles by the fuel consumption and pollutant emissions per vehicle mile in Table 9, we obtained the results in Table 10. Due to TRAX, 1,000 gallons of gasoline are saved and 19,400 pounds of $\mathrm{CO}_{2}$ emissions are not emitted each day. Annually, this translates to saving 624,300 gallons of gasoline and not emitting 7,084,600 pounds of $\mathrm{CO}_{2}$.

TABLE 9.

EPA Average Emissions and Fuel Consumption for Passenger Cars

\begin{tabular}{|c|c|}
\hline Pollutant/Fuel & $\begin{array}{c}\text { Emission \& Fuel Consumption Rates } \\
\text { (per mile driven) }\end{array}$ \\
\hline VOC & 1.034 grams (g) \\
\hline $\mathrm{THC}$ & $1.077 \mathrm{~g}$ \\
\hline $\mathrm{CO}$ & $9.400 \mathrm{~g}$ \\
\hline $\mathrm{NO}_{\mathrm{X}}$ & $0.693 \mathrm{~g}$ \\
\hline $\mathrm{CO}_{2}$ & $368.4 \mathrm{~g}$ \\
\hline Gasoline Consumption & 0.04149 gallons (gal) \\
\hline
\end{tabular}

Source: Average Annual Emissions and Fuel Consumption for GasolineFueled Passenger Cars and Light Trucks, EPA, http://www.epa.gov/otaq/ consumer/420f08024.pdf.

TABLE 10. Effect of TRAX on Energy Consumption and Emission Reduction

\begin{tabular}{|c|c|c|c|c|c|}
\hline Pollutant/Fuel & $\begin{array}{l}\text { Emission \& Fuel } \\
\text { Consumption Rates } \\
\text { (per mile driven) }\end{array}$ & $\begin{array}{c}\text { Traffic } \\
\text { Reduction }\end{array}$ & Calculation & $\begin{array}{c}\text { Daily Reduction } \\
\text { of Emission } \\
\text { \& Fuel } \\
\text { Consumption }\end{array}$ & $\begin{array}{c}\text { Annual } \\
\text { Reduction of } \\
\text { Emission \& Fuel } \\
\text { Consumption }\end{array}$ \\
\hline VOC & $1.034 \mathrm{~g}$ & \multirow{6}{*}{$10,400 \mathrm{vpd}$} & $\begin{array}{c}1.034 \mathrm{~g} / \mathrm{mi}) \times(2.3 \mathrm{mi}) \times(10,400 \mathrm{vpd}) \times \\
(1 \mathrm{lb} / 454 \mathrm{~g})\end{array}$ & $54.48 \mathrm{lb}$ & $19,900 \mathrm{lb}$ \\
\hline THC & $1.077 \mathrm{~g}$ & & $\begin{array}{c}(1.077 \mathrm{~g} / \mathrm{mi}) \times(2.3 \mathrm{mi}) \times(10,400 \mathrm{vpd}) \times \\
(1 \mathrm{lb} / 454 \mathrm{~g})\end{array}$ & $56.74 \mathrm{lb}$ & $20,700 \mathrm{lb}$ \\
\hline $\mathrm{CO}$ & $9.400 \mathrm{~g}$ & & $\begin{array}{c}(9.400 \mathrm{~g} / \mathrm{mi}) \times(2.3 \mathrm{mi}) \times(10,400 \mathrm{vpd}) \times \\
(1 \mathrm{lb} / 454 \mathrm{~g})\end{array}$ & $495.26 \mathrm{lb}$ & $180,800 \mathrm{lb}$ \\
\hline $\mathrm{NO}_{\mathrm{X}}$ & $0.693 \mathrm{~g}$ & & $\begin{array}{c}(0.693 \mathrm{~g} / \mathrm{mi}) \times(2.3 \mathrm{mi}) \times(10,400 \mathrm{vpd}) \times \\
(1 \mathrm{lb} / 454 \mathrm{~g})\end{array}$ & $36.51 \mathrm{lb}$ & $13,300 \mathrm{lb}$ \\
\hline $\mathrm{CO}_{2}$ & $368.4 \mathrm{~g}$ & & $\begin{array}{c}(368.4 \mathrm{~g} / \mathrm{mi}) \times(2.3 \mathrm{mi}) \times(10,400 \mathrm{vpd}) \times \\
(1 \mathrm{lb} / 454 \mathrm{~g})\end{array}$ & $19,400 \mathrm{lb}$ & $7,084,600 \mathrm{lb}$ \\
\hline $\begin{array}{c}\text { Gasoline } \\
\text { Consumption }\end{array}$ & $0.04149 \mathrm{gal}$ & & $(2.3 \mathrm{mi}) \times(10400 \mathrm{vpd}) /(24.1 \mathrm{mi} / \mathrm{gal})$ & $992.53 \mathrm{gal}$ & $362,300 \mathrm{gal}$ \\
\hline
\end{tabular}




\section{Conclusion and Discussion}

There is an important debate over the value of the LRT for mitigation of traffic congestion, energy consumption, and air pollution. To accurately assess LRT effect on traffic, it is necessary to use a quasi-experimental analysis. A cross-sectional analysis (of the sort that is common in ridership modeling) can establish only correlation, not causation). This study provides some of the strongest evidence to date of LRT effects on traffic, energy consumption, and air pollution. We found other studies in our literature review that also attempted to measure and quantify the impacts of LRT on traffic congestion, but none of these other studies used a controlled quasi-experimental research design. Our quasi-experiment focuses on the "treatment" of introducing the 2.3-mile extension of the TRAX system with service continuing from Downtown Salt Lake City to the Rice-Eccles Stadium on the University of Utah campus in December 2001 and the additional 1.5-mile extension to the University Medical Center September 2003.

In the short-term analysis, we found that between 2001 and 2004, after the introduction of the "treatment," the AADT on 400/500 South decreased to 10,100 vpd. This is roughly equal to the increase in transit ridership $(6,800)$ and the increase in AADT on parallel streets $(3,600)$. When this comparison was drawn out to 1999 , we found that the decrease in AADT was $17,900 \mathrm{vpd}$. TRAX ridership had been growing prior to the extension of the line to the Rice-Eccles Stadium, but it continued to increase after 2002 before leveling off during 2008-2012.

In the medium-term analysis, we compared two streets that we consider to be comparable to 400/500 South before the University TRAX line opened: 1300 East and 700 East, which had virtually identical average AADT to 400/500 South. The results showed that the average AADT on these two streets was 7,500 vpd higher than the AADT on 400/500 South after the TRAX line opened (between 2006 and 2012).

In the final quasi-experimental analysis, the building square footage increased 12.8 percent between 1999 and 2009 in the half-mile buffer around 400/500 South. Accordingly, 7.9 percent of new trips were generated by these new developments on the corridor. Our estimates indicated that vpd should have been 44,000 on this corridor, but, instead, we found this number to be 22,300. Therefore, because of TRAX, the vpd was reduced by 21,700 . Based on our estimates, LRT along 400/500 South saves about 362,300 gallons of gasoline and prevents about 7 million pounds of $\mathrm{CO}_{2}$ from being emitted each year.

AADT on 400/500 South has been relatively steady since 2005 . The theory of induced traffic suggests that, in the very long-term, the road will fill to capacity due to redevelopment in the corridor and additional development in the region. However, the university is not planning to expand its enrollment, and there is only so much redevelopment that can occur within the corridor given the normal useful lives of buildings (hundreds of years for residential properties, decades for non-residential properties). Perhaps the best chance for redevelopment is the conversion of surface parking lots to active uses with structured parking, which has already begun to occur (for example, at Trolley Square). Nonetheless, we would be hard pressed to project when traffic volumes will begin to increase in the corridor and see no evidence of it through 2012, 10 years after line was extended to the University Medical Center. 
This study is subject to important caveats. One is in regard to the external validity of this study, or lack thereof. We cannot guarantee that LRT would have the same effect on traffic at other locations given that our study area (from downtown Salt Lake City to University of Utah) is unique. The University of Utah is a major center of employment for Salt Lake City and the surrounding county, and students and staff have free access to TRAX. Locations with employers who do not subsidize the cost of riding LRT may not see the ridership levels and decreases in vehicle travel trips that the university does.

More important is a caveat related to internal validity. Our design is quasi-experimental, not experimental, and, hence, we must be careful not to overstate our ability to draw causal inferences. The dip in traffic on 400/500 South could, theoretically, be due to some cause other than the extension of TRAX to the university. There are numerous threats to the validity of the simple pre-intervention/post-intervention comparison without a control group (Shadish et al. 2002). The two control groups used in this quasi-experimental design (parallel streets in Figure 4 and perpendicular streets in Figure 6) are not, of course, a perfect match with 400/500 South, the treated street. Other factors (such as different redevelopment patterns in their corridors) could cause them to have different traffic patterns than 400/500 South in the absence of TRAX.

A counterfactual is something that is contrary to fact. In an experiment, we observe what did happen when people received a treatment (in this case, the availability of LRT service). The counterfactual is knowledge of what would have happened to those same people if they simultaneously had not received treatment. An effect (of a treatment) is the difference between what did happen and what would have happened (Shadish et al. 2002, p. 5).

We cannot actually observe a counterfactual, so, instead, we selected a control group that came as close to representing the counterfactual as possible. What would have happened in the absence of LRT in the transit corridor? We simply chose streets that serve the same quadrant of the region (northeast Salt Lake City) and should be affected by the same forces when it comes to traffic. In a quasi-experimental design such as this one, the control group (actually, the comparison group) is never identical to the experimental group. If it was, this would be a true experiment. Also, we estimated traffic reduction several ways in an attempt to bound likely impacts of TRAX. That is, we established several counterfactuals for purposes of the quasi-experiment. The different estimates are all in the "same ballpark."

\section{Acknowledgments}

This study was funded with a grant from the National Institute for Transportation and Communities (NITC), a federally-funded University Transportation Center.

\section{References}

American Public Transportation Association. 2013. Public transportation ridership report: Second quarter 2013. Accessed October 23, 2013. http://www.apta.com/ resources/statistics/Pages/ridershipreport.aspx. 
Bailey, L., P. L. Mokhtarian, and A. Little. 2008. The broader connection between public transportation, energy conservation and greenhouse gas reduction. Accessed October 23, 2013. http://www.apta.com/gap/policyresearch/Documents/land_use.pdf.

Bhattacharjee, S., and A. Goetz. 2012. Impact of light rail on traffic congestion in Denver. Journal of Transport Geography 22: 262-270.

Cervero, R., and J. Murakami. 2010. Effects of built environments on vehicle miles traveled: Evidence from 370 US urbanized areas. Environment and Planning A 42: 400-418.

Duranton, G., and M. A. Turner. 2011. The fundamental law of road congestion: evidence from US cities. American Economic Review 101: 2616-2652.

Ewing, R., K. Bartholomew, S. Winkelman, J. Walters, and D. Chen. 2008. Growing Cooler: The Evidence on Urban Development and Climate Change. Washington DC, Urban Land Institute.

Ewing, R., S. Hamidi, A. C. Nelson, and J. Grace. 2014. Structural equation models of VMT growth in U.S. urbanized areas. Urban Studies, published on-line first.

Garrett, T. A. 2004. Light rail transit in America: Policy issues and prospects for economic development. Accessed October 23, 2013. http://www.stlouisfed.org/community_ development/assets/pdf/light_rail.pdf.

Goldstein, D. 2007. Saving Energy, Growing Jobs: How Environmental Protection Promotes Economic Growth, Profitability, Innovation, and Competition. Bay Tree Publishing.

Hyman, G., and L. Mayhew. 2002. Optimizing the benefits of road user charging. Transport Policy 9(2002): 189-207.

Institute of Transportation Engineers (ITE). 2012. Trip Generation, 9th ed. ITE, Washington, DC.

Lee, S., and M. Senior. 2013. Do light rail services discourage car ownership and use? Evidence from Census data for four English cities. Journal of Transport Geography 29: $11-23$.

Litman, T. 2007. Evaluating rail transit benefits: A comment. Transport Policy 14(2007): 94-97.

Litman, T., 2012. Rail transit in America A comprehensive evaluation of benefits. Accessed October 23, 2013. http://www.vtpi.org/railben.pdf.

O'Toole, R. 2008. Does rail transit save energy or reduce greenhouse gas emissions? Policy Study No. 614. http://object.cato.org/sites/cato.org/files/pubs/pdf/pa-615.pdf.

Parry, I., and K. Small. 2009. Should urban transit subsidies be reduced? American Economic Review 99(3): 700-724.

Schrank, D., B. Eisele and T. Lomax. 2012. TTI's 2012 Urban Mobility Report. Texas A\&M Transportation Institute. Accessed October 23, 2013. http://d2dt15nnlpfrOr.cloudfront.net/tti.tamu.edu/documents/mobility-report-2012.pdf. 
Senior, M. 2009. Impacts on travel behaviour of Greater Manchester's light rail investment (Metrolink Phase 1): Evidence from household surveys and Census data. Journal of Transport Geography 17: 187-197.

Shadish, W. R., T. D. Cook, and D. T. Campbell. 2002. Experimental and quasi-experimental designs for generalized causal inference. Boston, MA, Houghton Mifflin.

Transportation Research Board (TRB). 2005. Special Report 282, "Does the Built Environment Influence Physical Activity? Examining the Evidence." Washington DC.

Warburton, N. 2007. TRAX ridership numbers pit UTA, critics. Deseret News. Accessed November 4, 2013. http://www.deseretnews.com/article/695195968/TRAX-ridership-numbers-pit-UTA-critics.html.

Winston, C. and A. Langer. 2006. Effect of government highway spending on road users' congestion costs. Journal of Urban Economics 60(2): 362-382.

\section{About the Authors}

ReID EwING (ewing@arch.utah.edu), Ph.D., is a Professor of City and Metropolitan Planning at the University of Utah, associate editor of the Journal of the American Planning Association, and a columnist for Planning magazine. His "Travel and The Built Environment: A Meta-Analysis" with Robert Cervero won the best article of the year award from the Journal of the American Planning Association in 2010. His new books are Measuring Urban Design: Metrics for Livable Places, published by Island Press, and Pedestrian- and Transit-Oriented Design, published by the Urban Land Institute and the American Planning Association.

GUANG TIAN (guang.tian@utah.edu) is currently a doctoral student in the Department of City and Metropolitan Planning at the University of Utah. He has a master's degree of GIS, and his research interests include travel behavior and the built environment, public transportation, and trip generation for walking and biking.

Allison Spain (spain@arch.utah.edu) is a 2013 graduate of the Master of Urban and Environmental Planning Program at the University of Virginia. She currently works as a program manager in the Department of City \& Metropolitan Planning's Metropolitan Research Center at the University of Utah.

J. P. Goates (jgoates@gmail.com) is with the Department of City and Metropolitan Planning at the University of Utah. 